Running Head: Indigenous Australian Students

\title{
Self-concepts and Educational Outcomes of Indigenous Australian Students in Urban and Rural School Settings
}

\author{
Alexander Seeshing Yeung \\ Rhonda G. Craven \\ Jinnat Ali
}

\begin{abstract}
Author Note
The research was funded by the Australian Research Council and the Department of Education and Community, New South Wales, Australia.
\end{abstract}

Keywords: Indigenous Australian; self-concept; rural; schools 


\begin{abstract}
Indigenous Australians have been known to be disadvantaged in many ways although higher art and physical self-concepts have been reported with Indigenous samples. Given recent research demonstrating the reciprocal effects of achievement and self-concept in academic domains, Indigenous students may experience further disadvantages in both academic performance and self-concept. A sample of Indigenous and non-Indigenous students $(N=$ 1,342) from schools in New South Wales (NSW), Australia were asked to respond to a survey measuring: 5 domains of self-concept (i.e., school, reading, maths, art, and physical abilities), 2 learning-related factors (enjoyment and participation), and a self-assessment of their school work. Their scores in a NSW state-wide assessment of students' literacy and numeracy were also obtained. Confirmatory factor analysis established the self-concept and learning-related factors. Multivariate analysis of variance (MANOVA) using a 2 (identity: Indigenous vs. NonIndigenous) x 2 (region: urban vs. rural) design found significant effects of identity for all variables except for art self-concept. That is, non-Indigenous students scored higher than Indigenous students in literacy and numeracy tests, self-concepts, learning-related factors, and self-ratings of school work, irrespective of region. The results did not support previous research demonstrating a relatively higher art self-concept for Indigenous children based on stereotypical perspectives. These results imply, that educators would be well advised to not assume stereotypic differences between Indigenous and non-Indigenous Australian students or assume a great difference between Indigenous students from urban and rural school settings. However, there seems to be a need for improving the school environment so as to promote Indigenous students’ performance and enjoyment of school life.
\end{abstract}


Many policy documents around the world advocate the development of a positive self-concept as an important educational outcome (e.g., Organization for Economic Cooperation and Development, 2003). This is because students with a higher self-concept academically are more likely to display better behaviour, maintain psychological wellbeing, and perform well in achievement tests (Craven \& Yeung, 2008). However, Indigenous Australians seem to be disadvantaged in both academic achievement and academic self-concepts relative to their nonIndigenous peers (Bodkin-Andrews, Ha, Craven, \& Yeung, 2010). Indigenous Australians seem to have higher self-concepts in art and physical ability, but not in academic work (Craven \& Marsh, 2004; Watkins, Lam, \& Regmi, 1991). Given the well documented findings that are consistent across numerous studies showing strong domain-specific relations between selfconcept and achievement (e.g., Marsh \& Craven, 2006; Craven \& Yeung, 2008), Indigenous students' strengths in art and physical domains are unlikely to facilitate their performance in academic domains. Further complicating the issue of potential disadvantages Indigenous students may face is the apparent difference of opportunities in urban and rural school settings. In the present study, we compared the self-concepts, achievements, and other learning outcomes of Indigenous and non-Indigenous students in urban and rural schools. We also examined the relations between different self-concepts and educational outcomes. Our major purpose was to delineate whether students with an Indigenous background or those in a rural setting would be more disadvantaged in terms of self-concepts and educational outcomes.

\section{Importance of Self-concept}

Self-concept is a term that has been used interchangeably with many other terms related to the self until Shavelson, Hubner, and Stanton (1976) clearly defined it and developed a theoretical model of self-concept. They suggested that self-concept is highly structured, multifaceted, and hierarchical. Subsequently, numerous researchers have found strong support for this structure (e.g., Marsh \& Craven, 2006; Yeung et al., 2000; Yeung \& Wong, 2004). In the academic domain, students' self-concepts are primarily their self-perceptions about themselves in academic work and these perceptions influence academic behaviours and educational outcomes. Numerous studies have shown that self-perceptions and beliefs do influence educational outcomes for students with different backgrounds (e.g., Carroll, Houghton, Wood, Perkins, \& Bower, 2007; Chong, 2007; Shin, Lee, \& Kim, 2009; Yeung \& Lee, 1999). A body of international research has shown that self-concept shares a reciprocal and mutually reinforcing causal relationship with achievement and other desirable outcomes (see Marsh \& Craven, 2006 for an overview). More importantly, this mutually reinforcing relation is domain specific such that self-concept in the maths domain, for example, influences maths outcomes, which also subsequently influence maths self-concept; but these mutual relations are specific within the maths domain and hence do not transfer to other domains of self-concept (e.g., verbal).

An important contribution of research findings showing the strong multidimensionality of self-concept is the practical applications for educational interventions that focus on specific self-concept dimensions of interest. Craven and Yeung (2008) describe some of these interventions underpinned by this multidimensional perspective. They demonstrated that by focusing on the academic aspects of school life during transition from primary to secondary school, peer support interventions benefit students' academic outcomes but not social outcomes. In contrast, by focusing on the social dimension during transition, benefits were found in social variables but not academic outcomes. Hence if we enhance self-concept in an appropriate way applying the principle of domain specificity, we are able to enhance selfconcept in a specific domain so as to positively influence educational outcomes within that specific domain. However, despite this knowledge that should enable practitioners to devise effective intervention strategies, the implications of the recent advances in self-concept 
research have not been fully exploited for effective educational applications (Craven \& Yeung, 2008). In fact, in many educational settings, students are being disadvantaged, and may remain disadvantaged because it is unlikely for them to reach an optimal level of self-concept (e.g., Bodkin-Andrews et al., 2010).

\section{Indigenous Australian Students' Self-concept}

Indigenous Australian students are known to suffer from multiple socio-economic disadvantages (Claremont, 2008; Cooke, Mitrou, Lawrence, Guimond, \& Beaven, 2007; Hill, Barker, \& Vos, 2007; Ring \& Brown, 2003). Although recent policies and educational programs have attempted to eliminate educational inequality, research seems to show that Indigenous Australians have remained one of the most disadvantaged Indigenous populations in the world (Cooke et al., 2007; Hill et al., 2007; Ring \& Brown, 2003) and the most disadvantaged among other Australians in terms of educational outcomes. For example, poor school retention rates are a serious concern with Indigenous Australian students (Claremont, 2008) whereby the number of Indigenous Australian students progressing into the final year of secondary schooling $\left(12^{\text {th }}\right.$ grade) is much lower $(42.9 \%)$ compared to non-Indigenous students (75.6\%) (Australian Bureau of Statistics and Australian Institute of Health and Welfare, 2008). Hence it is apparent that Indigenous students generally do less well academically than their non-Indigenous peers.

To explain the academic disadvantage of Indigenous students, researchers have gone beyond the previous emphasis on the socio-economic disadvantages these students experience (see Jonas, 2003; Rowe, 2003) to examine psychological factors that drive academic success. Researchers have started to investigate the psychological wellbeing of Indigenous students (e.g., Pedersen \& Walker, 2000; Purdie \& McCrindle, 2004), their self-concept (Craven \& Marsh, 2004), and their motivation in school work (Martin, 2006). These new research findings have broadened our knowledge about the disadvantage Indigenous students suffer and have enabled researchers to devise appropriate interventions that may counter it.

Nevertheless, there is a need to further understand how Indigenous Australian students compare to non-Indigenous students in important psychological variables that drive potential. After all, cultural differences may exist in students' self-perceptions and motivation in school, which may lead to quite different impacts on educational outcomes (see Shin et al., 2009). To explore potential differences, a few researchers have conducted some comparative studies, and most findings seem to be consistent with stereotypical expectations. For example, Watkins et al. (1991) found that Australian adolescents tended to have higher non-academic self-concepts than Napalese and Philipino students. Comparing Indigenous and non-Indigenous Australian students, Craven and Marsh (2004) found that Indigenous students had significantly higher levels of general, appearance, physical, and art self-concepts, but they were significantly lower in math, school, English, honesty, emotional, opposite and same sex relations self-concepts. Hence it seems that Indigenous students tend to have lower academic self-concepts but somewhat higher non-academic self-concepts. Given this finding of relatively lower academic self-concepts and the known fact of a relatively lower socio-economic status of Indigenous families, the disadvantage of Indigenous students is probably exacerbated with a combination of socioeconomic and psychological factors.

\section{Rural Education in Australia}

For the definition of location in the present investigation, we chose geographic distance as the defining factor. As James, Baldwin, Helpworth, McInnis, and Stephanou (1999) have noted, the definition and measurement of rurality is "notoriously difficult" (p. 5). Looker and Dwyer (1998) have commented that 'rural' has been predominantly used as a synonym for 'non-metro'. Western, McMillan, and Durrington (1998) suggest that the definition of 'rural' may be categorized into four types: social representational, descriptive, sociocultural, and 
politico-economic. In general, rurality is often defined in terms of a mix of at least some of these types. However, rurality has been defined more often in terms of population density and distance (Kenyon et al, 2001), accessibility to services (Department of Health and Aged Care (2001), and other factors (Henry, 1998; Wyn, Stokesm, \& Stafford, 1998).

The disadvantages of students in rural communities have been explored and discussed in a number of studies. In general, young people in rural communities are found to be underrepresented in post-compulsory education (James et al., 1999; Lamb, Dwyer, \& Wyn, 2000), and the major concerns for rural Australians include access to educational opportunities, quality of educational provisions, financial issues, and attitudes towards education (Alloway, Gilbert, Gilbert, \& Muspratt, 2004). Further exacerbating the situation is the difficulties of attracting, retaining, and then supporting rural teachers (HREOC, 2000; Kenyon et al, 2001; MCEETYA, 2001). As a result, students may be less satisfied with education in rural areas (Office of Youth Affairs, 1997). Nevertheless, Alloway et al. (2004) found that students in urban and rural school setting may have similarly negative perceptions of their education although as James et al. (1999) have documented, there are likely to be more barriers to schooling for rural students including: high costs, forced social dislocation, inexperienced teachers, narrow curriculum choice, little family and community encouragement to continue with their education, and a lack of help in negotiating and understanding educational possibilities and opportunities available.

In their focus group interviews with students in rural Australian schools, Alloway et al. (2004) found it difficult to really define a distinctive 'rurality' factor. Students in their study generally valued the prospects of further education and training regardless of location. The only distinct feature found with the rural sample was their perception of difficulties involved in “actually being able to reach it and touch it' when aspirations for further education is concerned. Hence although rural students may be somewhat disadvantaged, as a result of modernization and globalization leading to improved school environments in continually improving rural school settings, it is uncertain whether the previous disadvantages rural students experience is still prevalent.

\section{The Present Investigation}

In this study, we asked a sample of Indigenous and non-Indigenous students from schools in New South Wales (NSW), Australia to respond to a survey on their self-concepts, their enjoyment and participation in school work, and to rate their own ability in school work. We first attempted to validate the integrity of the instrument using confirmatory factor analysis (CFA), and then used it to compare Indigenous and non-Indigenous students from urban and rural schools. We also obtained students' achievement scores in reading and maths. We expected that Indigenous students would have lower achievement scores than non-Indigenous students. Furthermore, based on previous findings (e.g., Craven \& Marsh, 2004), we hypothesized that Indigenous students would have lower academic self-concepts but higher non-academic self-concepts.

\section{Participants}

\section{Method}

Students from 52 secondary schools in New South Wales, Australia $(N=1,342)$ participated in this study. The schools were public schools randomly selected from urban and rural areas and only schools with an Indigenous population of $10 \%$ or more were invited to participate. The students were from Year 3 (age about 10) to Year 6 (age about 13). In this sample, 45.1\% were boys. Of the 52 schools, 25 were urban schools (located within an average of $51 \mathrm{~km}$ from the city of Sydney) and 27 were rural schools (located in rural areas above $305 \mathrm{~km}$ from Sydney). The Indigenous Australian students were identified from their self-reported ethnicity as of Indigenous or Indigenous and Torres Strait Islander (ATSI) 
background. A total of 241 Indigenous Australian students were sampled in the urban schools, and 331 were non-Indigenous. Of the non-Indigenous students, 430 came from urban schools and 340 came from rural schools.

\section{Material and Procedure}

In a survey, the students were asked to rate their self-concept for 5 factors (school, reading, maths, art, and physical self-concepts), two learning-related variables (enjoyment and participation), and a self-rating on academic ability. Background variables included: age, gender, ethnicity, and language background. Two achievement outcomes (reading achievement and maths achievement test scores) were also obtained.

Self-concept factors. They were adapted from Marsh's (1990) Academic Self Description Questionnaire instrument, one of the most widely used self-concept instruments for different cultures (e.g., Bodkin-Andrews et al., 2010; Worrell, Watkins, \& Hall, 2008; Yeung \& Lee, 1999). The factors were: (1) School self-concept (e.g., "Work is easy for me in most subjects"), (2) Reading self-concept (e.g., "I am good at reading”), (3) Mathematics self-concept (e.g., "I learn things quickly in mathematics”). (4) Art self-concept (e.g., "I enjoy Art classes”), and (5) Physical self-concept (e.g., "I enjoy sports and games”).

Learning-related variables. There were four items for each learning-related factor (enjoyment and participation): (1) Enjoyment, which was adapted from the Craven et al. (2005) School Enjoyment Scale (e.g., "I enjoy being at school”), and (2) Participation, which was adapted from Leithwood, Jantzi, and Steinbach’s (1999) Leadership and Engagement Scale (e.g., "I participate when we discuss things in class").

Achievement outcomes. The achievement scores for reading and maths were scores in a state-wide standardized test organized by the Educational Measurement and School Accountability Directorate (EMSAD) of the NSW Department of Education and Training. They were a shorter version of the NSW Basic Skills Test (approximately 20 minutes rather than 40 minutes in duration) covering reading and numeracy (http://www.schools.nsw.edu.au/learning/emsad/index.php). The students' EMSAD scores in the state-wide reading and tests used here were in percentages but because the test items were not the same in different year levels, mean differences could not be examined across year levels. The scores were standardised within each year level in the analysis so as to enable us to examine the relations between self-concepts and achievement outcomes in the separate domains of reading and maths.

Self-rating. Students were asked to rate themselves in terms of their ability in school work. This single-item measure was used to provide a stronger validation of the self-concept factors. Because the self-rating was about academic work, students' self-ratings were expected to correlate more highly with academic self-concepts (school, reading, and maths) than with non-academic self-concepts (art and physical).

Informed consent was obtained from the school and the parents, and data were collected only from those students who agreed to participate. The survey was administered in large groups by a research assistant who read each item aloud so as to minimize problems arising from students with reading difficulties. The students responded to the survey items on a 5point scale $(1=$ strongly disagree to $5=$ strongly agree $)$. That is, higher scores reflected more favourable self-concepts.

\section{Statistical Analysis}

In order to facilitate valid group comparisons, the integrity of the measures needed to be established. First, the Cronbach's alpha estimate of internal consistency of each a priori factor was examined. Then the factor structure of a 5-factor model with 40 items was scrutinized with a CFA model (Model 1). Next, we tested a model with the five self-concept factors together with two learning-related factors (enjoyment and participation) and one self-rating 
factor with a single item (Model 2). Finally, we tested Model 3 with five self-concept factors (40 items), two learning-related factors (8 items), achievement scores (2 items), and self-rating (1 item). The procedures for conducting CFA have been described elsewhere (e.g., Byrne, 1998; Jöreskog \& Sörbom, 2005) and are not further detailed here. The CFA was conducted with LISREL software (Jöreskog \& Sörbom, 2005). Model fit and parameter estimates are reported on the basis of commonly accepted requirements for CFA (see Byrne, 1998; Jöreskog \& Sörbom, 2005; Browne \& Cudeck, 1993). Based on the factors established in the CFA model, we examined the patterns of correlations among the three factors for each group. Then, using the variables established from the CFA as dependent variables, a multivariate analysis of variance (MANOVA) was conducted for group comparisons. A 2 (identity: Indigenous vs. Non-Indigenous) x 2 (region: urban vs. rural) design was used.

\section{Confirmatory Factor Analysis}

\section{Results}

The alpha reliability of each scale with multiple indicators was acceptable (all $\alpha$ s $>.80$ ), providing support for the a priori scales (Table 1). The CFA models converged to proper solutions with reasonable fit, with both NNFI and CFI $>.95$. Model 1 with five self-concept factors had $\chi^{2}(680 d f)=6324$, NNFI $=.97$, CFI $=.98$, RMSEA $=.079$. Model 2 with five self-concepts, two learning-related factors, and one self-rating had $\chi^{2}(1100 d f)=10111$, NNFI $=.97, \mathrm{CFI}=.97$, RMSEA $=.078$. Model 3 with five self-concepts, two learningrelated factors, two achievement scores, one self-rating had $\chi^{2}(1182 d f)=10332$, NNFI $=.97$, $\mathrm{CFI}=.97$, RMSEA $=.076$. Table 2 presents the factor loadings and factor correlations for Model 3. All factor loadings were acceptable (all > .50). The largest factor correlation was .74, indicating that all factors were clearly distinguishable from each other. This result provided support for the construct validity of the measures, which formed the basis for subsequent group comparisons.

\section{Insert Tables 1 and 2 about here}

The correlations between factors were logical. School self-concept was positively correlated with both reading and maths self-concepts ( $r s=.71$ and .74 respectively) and with both non-academic self-concepts - art and physical self-concepts ( $r s=.46$ and .42 respectively). The correlation between reading and maths self-concepts are high $(r=.48)$, compared to previous research (e.g., Yeung \& Lee, 1999; Yeung \& Wong, 2004), but this was consistent with the prediction that they would be clearly distinguishable from each other. As predicted, self-rating of school work was correlated highest with school self-concept, as self-rating was based on a general, overall impression of performance in school work and would be correlated with a general measure of academic self-concept. The evidence provided support for this prediction.

Enjoyment and participation as outcome variables are positively correlated with school self-concept ( $r s=.61$ and .58 respectively), which were higher than with the domain-specific self-concepts. This is also logical because both enjoyment and participation are domain-general variables and would be expected to correlate more with a domain-general self-concept measure. This relation between the domain-general and domain-specific variables is consistent with the Shavelson et al. (1976) hierarchical, multidimensional model of self-concept that was empirically reinforced by Yeung and Wong (2004).

For the relation between domain-specific self-concepts and domain-specific outcomes, reading self-concept was found to be positively correlated with reading achievement (i.e., reading EMSAD scores, $r=.16$ ). Maths self-concept was also found to be positively correlated with maths achievement (i.e., maths EMSAD scores, $r=.13$ ). Although these correlations were not particularly large, there was a clear pattern of domain specificity as the correlations between non-matching domains were close to zero. 
In sum, the general self-concept factor was more highly correlated with the domaingeneral variables (enjoyment, participation, self-rating) whereas the domain-specific selfconcepts (reading, maths) were more highly correlated with their respective domain-specific outcomes (achievement scores). This factor structure provided a strong measurement basis for subsequent group comparisons.

\section{Mean Comparisons}

For scales with multiple items, the scores for the items within each scale were averaged to form a scale score. The means and standard deviations are presented in Table 1, which also shows the means and standard deviations of the single items (reading achievement, maths achievement, and self-rating of school work). A 2 (identity: Indigenous vs. Non-Indigenous) x 2 (region: urban vs. rural) MANOVA was conducted with five self-concepts (i.e., school, reading, maths, art, and physical abilities), two learning-related factors (enjoyment and participation), one self-rating, and two achievement scores (reading and maths) as dependent variables.

\section{Insert Table 3 about here}

The MANOVA results are presented in Table 3. The analysis found statistically significant main effects of identity for 9 of the 10 variables (except art self-concept). For the three academic self-concepts (school, reading, and maths), Indigenous students had significantly lower scores than non-Indigenous students. That is, for school self-concept, Indigenous students ( $M$ s $=3.68$ and 3.70 for urban and rural, respectively) had significantly lower scores than non-Indigenous students $(M s=3.84$ and 3.80 for urban and rural, respectively). For reading self-concept, Indigenous students ( $M s=4.00$ and 3.83 for urban and rural, respectively) had significantly lower scores than non-Indigenous students ( $M \mathrm{~s}=$ 4.15 and 4.11 for urban and rural, respectively). For maths self-concept, Indigenous students (Ms $=3.69$ and 3.89, respectively) had significantly lower scores than non-Indigenous students (Ms $=3.95$ and 3.91, respectively).

For physical self-concept, the pattern was reversed. That is, Indigenous students ( $M \mathrm{~s}=$ 4.24 and 4.28, respectively) had significantly higher scores than non-Indigenous students (Ms $=4.15$ and 4.18, respectively). However, for art self-concept, Indigenous students ( $M s=4.40$ and 4.33, respectively) did not differ from non-Indigenous students ( $M s=4.44$ and 4.36 , respectively).

Indigenous students had lower scores in enjoyment of school (Ms = 3.66 and 3.61, respectively) than non-Indigenous students ( $M s=3.94$ and 3.76, respectively). They also had lower scores in participation ( $M \mathrm{~s}=4.05$ and 3.98, respectively) than non-Indigenous students ( $M \mathrm{~s}=4.28$ and 4.19 , respectively).

For achievement, Indigenous students had significantly lower scores in both reading and maths. For reading, Indigenous students $(M s=-0.31$ and -0.39 , respectively for urban and rural) had significantly lower scores than non-Indigenous students $(M s=0.20$ and 0.37 , respectively). Also for maths, Indigenous students ( $M s=-0.26$ and -0.41 , respectively) had significantly lower scores than non-Indigenous students ( $M s=0.21$ and 0.32 , respectively). Similarly, Indigenous students' self-ratings of school work ( $M s=3.58$ and 3.66, respectively) were significantly lower than for non-Indigenous students ( $M s=3.83$ and 3.91, respectively).

In contrast, the main effects of region were not statistically significant. That is, no significant difference was found between the urban and rural groups in any of the variables. However, significant identity $\mathrm{x}$ region interaction effects were found in the achievement scores (Table 3). For reading achievement, Indigenous students in urban schools scored higher $(M=$ $0.31)$ than those in rural schools $(M=-0.39)$ whereas non-Indigenous students in rural schools $(M=0.37)$ did better than those in urban schools $(M=0.20)$. A similar pattern was found for maths achievement. That is, again, Indigenous students in urban schools scored higher $(M=$ - 
0.26) than those in rural schools $(M=-0.41)$ whereas non-Indigenous students in rural schools $(M=0.32)$ did better than those in urban schools $(M=0.21)$. However, the effect sizes were all very small (all partial $\eta^{2}<.10$ ). Therefore, even though there seem to be some subtle differences between Indigenous and non-Indigenous students in urban and rural settings, we need to caution that such differences should not be overstated.

\section{Comparisons of Correlations}

Table 4 presents the Pearson correlations among the 10 variables for the four groups of students. It can be seen that the correlations among most variables were logical and reasonable. However, although a similar pattern was found between Indigenous and non-Indigenous students, the correlations between academic self-concepts and academic achievements were stronger for non-Indigenous students. For example, for Indigenous students in urban schools, the correlation between reading self-concept and reading achievement $(r=.162)$ and between maths self-concept and maths achievement $(r=.173)$ were both positive (Table 4). For nonIndigenous students in urban schools, the correlation between reading self-concept and reading achievement $(r=.266)$ and between maths self-concept and maths achievement ( $r$ $=.306$ ) were also positive (Table 4). However, the respective correlations were clearly stronger for non-Indigenous students.

\section{Insert Table 4 about here}

Similar patterns were found with the rural students. For Indigenous students in rural schools, the correlation between reading self-concept and reading achievement $(r=.132)$ was positive, and the correlation between maths self-concept and maths achievement $(r=.070)$ was negligible (Table 4). For non-Indigenous students in rural schools, the correlation between reading self-concept and reading achievement $(r=.324)$ and between maths self-concept and maths achievement ( $r=.341$ ) were both positive, and much stronger than the respective correlations for the Indigenous students (Table 4). In sum, the consistent patterns found across urban and rural samples suggest that Indigenous students' academic self-concepts may not match their actual level of achievement. In other words, at least some Indigenous students may not have a realistic estimate of their academic abilities.

\section{Discussion}

Overall, Indigenous students were found to score lower in both reading and maths than their non-Indigenous peers That is, Indigenous students were clearly disadvantaged in terms of academic achievement, irrespective of region (urban or rural). However, the results also show more similarities than differences between Indigenous and non-Indigenous students in NSW, Australia for most other variables. Urban and rural schools basically did not display any difference at all. Identity x region interaction effects were found for both reading and maths achievement scores but the effect sizes were so small $\left(\eta^{2}<.005\right)$ that they may not be of any practical significance. For non-academic self-concepts, Indigenous students were found to be higher in physical self-concept but not in art self-concept (Table 1). Therefore, the results did not support previous research of a relatively higher art self-concept for Indigenous children based on stereotypical perspectives (Craven \& Marsh, 2004; Watkins et al., 1991) but did support previous research (Craven \& Marsh, 2004) demonstrating higher physical self-concept for Indigenous students.

Although the mean differences were statistically significant for these variables because of the large sample size, the small effect sizes may undermine the practical implications of such differences. That is, although Indigenous students were lower in school self-concept, and domain-specific self-concepts in reading and maths (Table 3), the relatively small difference between Indigenous and non-Indigenous students $\left(\eta^{2}<.01\right)$ may not account for the relatively large difference in achievement outcomes $\left(\eta^{2}\right.$ about .10). The consistent pattern of Indigenous students displaying lower scores for both achievements and self-concepts leads us to conclude 
that Indigenous students were disadvantaged in both. Therefore the enhancement of both performance in school work and academic self-concepts is a potentially potent intervention to contribute to breaking the vicious cycle of disadvantage experienced by Indigenous students. Nevertheless, an inspection of the correlations separately for Indigenous and non-Indigenous students (Table 4) found that the major issue may not solely lie with the mean differences between the sub-samples, but rather, the differential association between achievement scores and self-concepts. These findings imply that enhancing the academic self-concepts of Indigenous students may be more complex than previously thought in that the links between academic self-concept and achievement may need to be directly strengthened for the Indigenous students.

In essence, Indigenous students did not seem to have a good estimate of their abilities in reading and maths. Based on the reciprocal effects model of self-concept (Marsh \& Craven, 2006), maths self-concept would influence maths outcomes, which would subsequently influence maths self-concept, and this cycle will continue to further reinforce both achievement and self-concept. As such, a change in either achievement or self-concept, or both, may help the disadvantaged. However, the findings here seem to suggest that the situation for Indigenous students is more complicated than we expected. If Indigenous students do not have a reasonably accurate estimate of their competence and link this to their achievement as their non-Indigenous peers do, then attempts to enhance their self-concept with the hope of subsequent improvement in achievement may not bring desirable effects. Hence further research is needed to explore first whether the low association between achievement and selfconcept is a general phenomenon with Indigenous students, and second whether there are any effective ways to help Indigenous students develop a positive self-concept in school work that is clearly linked to their respective achievements.

In sum, we examined the self-concepts and their relations with achievement and other learning outcomes of Indigenous and non-Indigenous Australians in urban and rural schools. The results did not support previous claims of a relatively higher art self-concept for Indigenous children but showed a higher physical self-concept for Indigenous students. For academic variables, non-Indigenous students were found to score higher than Indigenous students in both tests of literacy and numeracy, self-concepts, learning-related factors, and self-ratings of school work, although the differences were not impressively large. Based on the findings, educators should not assume stereotypic differences between Indigenous and nonIndigenous Australian students or assume a great difference between urban and rural school settings.

\section{Implications for Those Working in the Schools}

1. There is a need for improving the school environment so as to promote Indigenous students' academic self-concept and academic achievement. Attempts to promote both self-concept and performance will have more sustainable effects.

2. The importance of a dual approach to promoting academic self-concept and academic achievement is beneficial to all students, irrespective of school location or whether they are Indigenous or non-Indigenous students.

3. We need to have high expectations for Indigenous students, which should be made explicit to them. Indigenous students seem to be less able to estimate their competence and to relate their self-concept realistically to their academic performance. As an individual's self-concept is developed through interactions with others, the feedback from teachers is of utmost importance in helping Indigenous students form a healthy expectation of themselves through optimal levels of expectation from their teachers.

4. Finally, the difference between Indigenous and non-Indigenous, and between urban and rural, students may be decreasing due to globalization and access to information in the 
modern age. It may no longer be realistic to assume that previous differences still exist. It will be advisable that practitioners keep to equity principles and facilitate optimal levels of development for every child towards academic excellence.

\section{References}

Alloway, N., Gilbert, P., Gilbert, R., \& Muspratt, S. (2004). Factors impacting on student aspirations and expectations in regional Australia. Canberra, Australia: Commonwealth of Australia.

Australian Bureau of Statistics \& Australian Institute of Health and Welfare (2008). The Health and Welfare of Australia's Indigenous and Torres Strait Islander peoples 2008. Canberra: Author.

Bodkin-Andrews, G., Ha, M. T., Craven, R. G., \& Yeung, A. S. (2010). Factorial invariance testing and latent mean differences for the Self-Description Questionnaire II (Short Version) with Indigenous and non-Indigenous Australian secondary school students. International Journal of Testing, 10, 47-79.

Browne, M. W., \& Cudeck, R. (1993). Alternative ways of assessing model fit. In K. A. Bollen \& J. S. Long (Eds.), Testing structural equation models (pp. 136-162). Newbury Park, CA: Sage.

Byrne, B. M. (1998). Structural equation modeling with LISREL, PRELIS, and SIMPLIS: Basic concepts, applications, and programming. Mahwah, NJ: Erlbaum.

Carroll, A., Houghton, S., Wood, R., Perkins, C., \& Bower, J. (2007). Multidimensional selfconcept: Age and gender differences in Australian high school students involved in delinquent activities. School Psychology International, 28, 237-256.

Chong, W. H. (2007). The role of personal agency beliefs in academic self-regulation: An Asian perspective. School Psychology International, 28, 63-76.

Claremont, Y. (2008). Cultural diversity in higher education (Australia): International students from Asia. International Journal of Learning, 15(6), 89-93.

Cooke, M., Mitrou, F., Lawrence, D., Guimond, E., \& Beavon, D. (2007). Indigenous wellbeing in four countries: An application of the UNDP'S Human Development Index to Indigenous Peoples in Australia, Canada, New Zealand, and the United States. BMC International Health and Human Rights, 7(9), 1-39.

Craven, R. G., Tucker, A., Munns, G., Hinkley, J., Marsh, H. W., \& Simpson, K. (2005). Indigenous students' aspirations: Dreams, perceptions and realities. Canberra: DEST, Commonwealth of Australia.

Craven, R. G., \& Marsh, H. W. (2004). The challenge for counsellors: Understanding and addressing Indigenous secondary students' aspirations, self-concepts and barriers to achieving their aspirations. Australian Journal of Guidance and Counselling, 14(1), 1633.

Craven, R. G., \& Yeung, A. S. (2008). International best practice in effective educational interventions: Why self-concept matters and examples from bullying, peer support, and reading research. In D. M. McInerney, V. E. Shawn, \& M. Dowson (Eds.), Research on sociocultural influences on motivation and learning. Vol. 8: Teaching and learning: International best practice (pp. 267-294). Greenwich, CT: Information Age.

Department of Health and Aged Care and the National Key Centre for Social Applications of Geographical Information Systems [GISCA] (2001). Measuring remoteness: Accessibility/Remoteness Index of Australia. Revised edition. Occasional papers: New Series Number 14. Canberra: Information and Research Branch, Department of Health and Aged Care. 
Henry, M. (1998). The functions of schooling: Perspectives from rural Australia. In E. Hatton (Ed.) Understanding Teaching: Curriculum and the Social Context of Schooling 2nd edition (pp.400-409). Sydney: Harcourt Brace.

Hill, K., Barker, B., \& Vos, T. (2007). Excess Indigenous mortality: are Indigenous Australians more severely disadvantaged than other Indigenous populations? International Journal of Epidemiology, 36(3), 580-589.

Human Rights and Equal Opportunity Commission [HREOC] (2000): Education access: National inquiry into rural and remote education. Canberra: Commonwealth of Australia.

James, R., Wyn, J., Baldwin, G., Helpworth, G., McInnis, C., \& Stephanou, A. (1999). Rural and isolated school students and their higher education choices. Commissioned Report No. 61. Melbourne: Centre for the Study of Higher Education and the Youth Research Centre, University of Melbourne.

Jonas, B. (2003). Social Justice Report 2003. Sydney: HREOC.

Jöreskog, K. G., \& Sörbom, D. (2005). LISREL 8.72: Structural equation modeling with SIMPLIS command language. Chicago: Scientific Software International.

Kenyon, P., Sercombe, H., Black, A. \& Lhuede, D. (2001). Creating better educational and employment opportunities for rural young people. A report to the National Youth Affairs Research Scheme. Hobart: Australian Clearinghouse for Youth Studies.

Lamb, S., Dwyer, P. \& Wyn, J. (2000) Non-completion of school in Australia: The changing patterns of participation and outcomes. LSAY Research Report No. 16. Melbourne: ACER.

Leithwood, K., Jantzi, D., \& Steinbach, R. (1999). Changing leadership for changing times. Buckingham, UK: Open University Press.

Looker, D. E. \& Dwyer, P. (1998) Education and negotiated reality: Complexities facing rural youth in the 1990s. Journal of Youth Studies, 1, 5-22.

Marsh, H. W. (1990). The structure of academic self-concept: The Marsh/Shavelson model. Journal of Educational Psychology, 82, 623-636.

Marsh, H. W., \& Craven, R. G. (2006). Reciprocal effects of self-concept and performance from a multidimensional perspective: Beyond seductive pleasure and unidimensional perspectives. Perspectives on Psychological Science, 1, 133-163.

Martin, A. J. (2006). A motivational psychology for the education of Indigenous students. Australian Journal of Indigenous Education, 35, 30-43.

Ministerial Council for Education, Employment, Training and Youth Affairs (MCEETYA) (2001). Taskforce on rural and remote education, training, employment and children's services. National framework for rural and remote education. Canberra: Ministerial Council on Education, Employment, Training and Youth Affairs.

Office of Youth Affairs, Tasmania (1997). Tasmania's rural and isolated young people issues, solutions and strategies. Hobart: Office of Youth Affairs, www.youth affairs.tas.gov.au/publications

Organization for Economic Cooperation and Development. (2003). Student engagement at school: A sense of belonging and participation. Paris: Author.

Pedersen, A., \& Walker, I. (2000). Urban Indigenous and Anglo-Australian children: Ingroup preference, self-concept, and teachers' academic evaluations. Journal of Community and Applied Social Psychology, 10, 183-197.

Purdie, N., \& McCrindle, A. (2004). Measurement of self-concept among Indigenous and non-Indigenous Australian students. Australian Journal of Psychology, 56(1), 50-62.

Ring, I., \& Brown, N. (2003). Indigenous and Torres Strait Islander health-implementation, not more policies. Journal of Australian Indigenous Issues, 6(3), 3-12. 
Rowe, K. J. (2003, October). The importance of teacher quality as a key determinant of students' experiences and outcomes of schooling. Keynote Address for the ACER Research Conference, Melbourne.

Shavelson, R. J., Hubner, J. J., \& Stanton, G. C. (1976). Self-concept: Validation of construct interpretations. Review of Educational Research, 46, 407-441.

Shin, J., Lee, H., \& Kim, Y. (2009). Student and school factors affecting mathematics achievement: International comparisons between Korea, Japan and the USA. School Psychology International, 30, 520-537.

Watkins, D., Lam, M. K., \& Regmi, M. (1991). Cross-cultural assessment of self-esteem: A Nepalese investigation. Psychologia, 34, 98-108.

Western, J., McMillan, J., \& Durrington, D. (1998). Differential access to higher education: The measurement of socioeconomic status, rurality and isolation. Canberra: Department of Employment, Education, Training and Youth Affairs.

Worrell, F. C., Watkins, M. W., \& Hall, T. E. (2008). Reliability and validity of self-concept scores in secondary school students in Trinidad and Tobago. School Psychology International, 29, 466-480.

Wyn, J., Stokes, H. \& Stafford, J. (1998). Young people living in rural Australia in the 1990s. Research report 16. Melbourne: Youth Research Centre, University of Melbourne.

Yeung, A. S., Chui, H. S., Lau, I. C. Y., McInerney, D. M., Suliman, R., \& Russell-Bowie, D. (2000). Where is the hierarchy of academic self-concept? Journal of Educational Psychology, 92, 556-567.

Yeung, A. S., \& Lee, F. L. (1999). Self-concept of high school students in China: Confirmatory factor analysis of longitudinal data. Educational and Psychological Measurement, 59, 431-450.

Yeung, A. S., \& Wong, E. K. P. (2004). Domain specificity of trilingual teachers' verbal selfconcepts. Journal of Educational Psychology, 96, 360-368. 
Table 1

Descriptive Statistics for Self-concept and Other Variables

\begin{tabular}{|c|c|c|c|c|c|c|c|c|c|}
\hline & \multicolumn{4}{|c|}{ Indigenous } & \multicolumn{4}{|c|}{ Non-Indigenous } & \multirow[t]{3}{*}{ Alpha } \\
\hline & \multicolumn{2}{|c|}{ Urban } & \multicolumn{2}{|c|}{ Rural } & \multicolumn{2}{|c|}{ Urban } & \multicolumn{2}{|c|}{ Rural } & \\
\hline & Mean & $\mathrm{SD}$ & Mean & SD & Mean & SD & Mean & $\mathrm{SD}$ & \\
\hline School-sc & 3.68 & 1.11 & 3.70 & 1.11 & 3.84 & 1.02 & 3.80 & 1.00 & .94 \\
\hline Reading-sc & 4.00 & 1.08 & 3.83 & 1.18 & 4.15 & 0.99 & 4.11 & 1.02 & .94 \\
\hline Maths-sc & 3.69 & 1.24 & 3.89 & 1.20 & 3.95 & 1.14 & 3.91 & 1.13 & .95 \\
\hline Art-sc & 4.40 & 0.90 & 4.33 & 1.03 & 4.44 & 0.89 & 4.36 & 0.99 & .95 \\
\hline Physical-sc & 4.24 & 0.84 & 4.28 & 0.81 & 4.15 & 0.79 & 4.18 & 0.82 & .86 \\
\hline Enjoyment & 3.66 & 1.30 & 3.61 & 1.39 & 3.94 & 1.24 & 3.76 & 1.28 & .92 \\
\hline Participation & 4.05 & 0.97 & 3.98 & 1.06 & 4.28 & 0.82 & 4.19 & 0.89 & .80 \\
\hline ReadAc & -0.31 & 0.91 & -0.39 & 0.85 & 0.20 & 0.97 & 0.37 & 1.03 & - \\
\hline MathsAc & -0.26 & 0.99 & -0.41 & 0.93 & 0.21 & 0.97 & 0.32 & 0.94 & - \\
\hline Self Rate & 3.58 & 0.96 & 3.66 & 1.02 & 3.83 & 0.92 & 3.91 & 0.87 & - \\
\hline
\end{tabular}

Note: $N=1$,342. Indigenous Urban ( $\mathrm{N}=241)$, Indigenous Rural ( $\mathrm{N}=331)$, Non-Indigenous Urban (430), NonIndigenous Rural (N=340). SC = self-concept. ReadAc $=$ Reading Achievement. MathsAc $=$ Maths Achievement. SelfRate $=$ Self-rating. 
Table 2

Factor Loadings and Inter-Scale Correlations in CFA (Model 3)

\begin{tabular}{|c|c|c|c|c|c|c|c|c|c|c|}
\hline \multicolumn{11}{|c|}{ CFA Factor Loadings } \\
\hline Items & Sch-sc & Read-sc & Maths-sc & Art-sc & Phys-sc & Enjoy & Partic & ReadAc & MathsAc & SelfRate \\
\hline 1 & 0.66 & 0.78 & 0.75 & 0.87 & 0.71 & 0.86 & 0.77 & 1.00 & 1.00 & 1.00 \\
\hline 2 & 0.80 & 0.76 & 0.84 & 0.86 & 0.59 & 0.90 & 0.71 & & & \\
\hline 3 & 0.76 & 0.87 & 0.78 & 0.89 & 0.55 & 0.86 & 0.57 & & & \\
\hline 4 & 0.89 & 0.81 & 0.87 & 0.88 & 0.65 & 0.83 & 0.77 & & & \\
\hline 5 & 0.81 & 0.88 & 0.80 & 0.78 & 0.81 & & & & & \\
\hline 6 & 0.88 & 0.76 & 0.89 & 0.79 & 0.74 & & & & & \\
\hline 7 & 0.76 & 0.84 & 0.87 & 0.79 & 0.83 & & & & & \\
\hline 8 & 0.89 & 0.77 & 0.90 & 0.73 & 0.58 & & & & & \\
\hline \multicolumn{11}{|c|}{ CFA Factor Correlations } \\
\hline Sch-sc & 1.00 & & & & & & & & & \\
\hline Read-sc & $0.71^{*}$ & 1.00 & & & & & & & & \\
\hline Maths-sc & $0.74 *$ & $0.48 *$ & 1.00 & & & & & & & \\
\hline Art-sc & $0.46^{*}$ & $0.44 *$ & $0.30 *$ & 1.00 & & & & & & \\
\hline Phys-sc & $0.42 *$ & $0.24 *$ & $0.39 *$ & $0.26 *$ & 1.00 & & & & & \\
\hline Enjoy & $0.61^{*}$ & $0.57^{*}$ & $0.44^{*}$ & $0.39 *$ & $0.20^{*}$ & 1.00 & & & & \\
\hline Partic & $0.58^{*}$ & $0.56^{*}$ & $0.45^{*}$ & $0.35^{*}$ & $0.27^{*}$ & $0.69 *$ & 1.00 & & & \\
\hline ReadAc & $0.06^{*}$ & $0.16^{*}$ & 0.04 & 0.03 & $-0.15 *$ & $0.09 *$ & $0.14^{*}$ & 1.00 & & \\
\hline MathsAc & 0.05 & 0.05 & $0.13^{*}$ & -0.02 & -0.04 & 0.03 & $0.08^{*}$ & $0.72 *$ & 1.00 & \\
\hline SelfRate & $0.38^{*}$ & $0.26^{*}$ & $0.35 *$ & $0.14^{*}$ & $0.21 *$ & $0.25 *$ & $0.32 *$ & $0.14 *$ & $0.16^{*}$ & 1.00 \\
\hline
\end{tabular}

Note: $N=1,342$. sc $=$ self-concept. Sch $=$ School. Read $=$ Reading. Phys $=$ Physical. Enjoy $=$ Enjoyment. Partic $=$

Participation. ReadAc $=$ Reading Achievement. MathsAc $=$ Maths Achievement. SelfRate $=$ Self-rating. Parameters estimates are completely standardized. * $p<.05$. 
Table 3

MANOVA Results

\begin{tabular}{|c|c|c|c|c|c|c|c|}
\hline & \multicolumn{2}{|c|}{ Identity (I) } & \multicolumn{2}{|c|}{ Region (R) } & \multicolumn{2}{|c|}{ I x R Interaction } & \multirow[t]{2}{*}{ MSE } \\
\hline & $F(1,1338)$ & Partial $\eta^{2}$ & $F(1,1338)$ & Partial $\eta^{2}$ & $F(1,1338)$ & Partial $\eta^{2}$ & \\
\hline School-sc & $5.05 *$ & .004 & 0.05 & .000 & 0.32 & .000 & 1.12 \\
\hline Reading-sc & $12.68 * *$ & .010 & 3.02 & .002 & 1.04 & .001 & 1.14 \\
\hline Maths-sc & $4.72 *$ & .004 & 1.38 & .001 & 3.26 & .002 & 1.37 \\
\hline Art-sc & 0.39 & .000 & 1.92 & .001 & 0.01 & .000 & 0.91 \\
\hline Physical-sc & $4.95 *$ & .004 & 0.54 & .000 & 0.01 & .000 & 0.66 \\
\hline Enjoyment & 8.93* & .007 & 2.30 & .002 & 0.86 & .001 & 1.69 \\
\hline Participation & $18.37 * *$ & .014 & 2.41 & .002 & 0.04 & .000 & 0.86 \\
\hline ReadAc & $146.98 * *$ & .099 & 0.82 & .001 & $5.54 *$ & .004 & 0.90 \\
\hline MathsAc & $126.60 * *$ & .086 & 0.12 & .000 & $6.09 *$ & .005 & 0.92 \\
\hline Self Rate & $20.01 * *$ & .017 & 2.25 & .002 & 0.00 & .000 & 0.88 \\
\hline
\end{tabular}

Note: $N=1,342 . \mathrm{sc}=$ self-concept. ReadAc $=$ Reading Achievement. MathsAc $=$ Maths Achievement.

SelfRate $=$ Self-rating. ${ }^{*} p<.05 .{ }^{* *} p<.001$. 
Table 4

Pearson Correlations of Variables

(1) Indigenous (Urban) Students $(N=241)$

\begin{tabular}{|c|c|c|c|c|c|c|c|c|c|c|}
\hline & Sch-sc & Read-sc & Math-sc & Art-sc & Phy-sc & Enjoy & Partic & ReadAc & MathsAc & S-Rate \\
\hline School-sc & 1 & & & & & & & & & \\
\hline Reading-sc & $.675^{* *}$ & 1 & & & & & & & & \\
\hline Maths-sc & $.665^{* *}$ & $.395^{* *}$ & 1 & & & & & & & \\
\hline Art-sc & $.460^{* *}$ & $.402^{* *}$ & $.324^{* *}$ & 1 & & & & & & \\
\hline Physical-sc & $.328^{* *}$ & $.156^{*}$ & $.338^{* *}$ & $.309^{* * *}$ & 1 & & & & & \\
\hline Enjoyment & $.481^{* *}$ & $.428^{* *}$ & $.319^{* *}$ & $.182^{* *}$ & .089 & 1 & & & & \\
\hline Participation & $.442^{* *}$ & $.467^{* *}$ & $.236^{* *}$ & $.315^{* *}$ & $.132^{*}$ & $.537^{* *}$ & 1 & & & \\
\hline ReadAc & .080 & $.162^{*}$ & .102 & .049 & -.119 & .016 & $.144^{*}$ & 1 & & \\
\hline MathsAc & .020 & .012 & $.173^{* *}$ & .007 & -.059 & -.079 & .047 & $.663^{* *}$ & 1 & \\
\hline S-Rate & $.302^{* *}$ & $.214^{* *}$ & $.305^{* *}$ & .050 & $.162^{*}$ & $.131^{*}$ & $.159^{*}$ & $.215^{*}$ & $.129^{*}$ & 1 \\
\hline
\end{tabular}

(2) Indigenous (Rural) Students $(N=331)$

\begin{tabular}{|c|c|c|c|c|c|c|c|c|c|c|}
\hline & Sch-sc & Read-sc & Math-sc & Art-sc & Phy-sc & Enjoy & Partic & ReadAc & MathsAc & S-Rate \\
\hline School-sc & 1 & & & & & & & & & \\
\hline Reading-sc & $.736^{* *}$ & 1 & & & & & & & & \\
\hline Maths-sc & $.713^{* *}$ & $.565^{* *}$ & 1 & & & & & & & \\
\hline Art-sc & $.448^{* *}$ & $.499^{* *}$ & $.257^{* *}$ & 1 & & & & & & \\
\hline Physical-sc & $.452^{* *}$ & $.330^{* *}$ & $.350^{* *}$ & $.227^{* *}$ & 1 & & & & & \\
\hline Enjoyment & $.611^{* *}$ & $.578^{* *}$ & $.445^{* *}$ & $.416^{* *}$ & $.235^{* *}$ & 1 & & & & \\
\hline Participation & $.554^{* *}$ & $.549^{* *}$ & $.425^{* *}$ & $.335^{* *}$ & $.242^{* *}$ & $.667^{* *}$ & 1 & & & \\
\hline ReadAc & .088 & $.132^{*}$ & .036 & .067 & -.049 & $.159^{* *}$ & $.208^{* *}$ & 1 & & \\
\hline MathsAc & .023 & .004 & .070 & -.065 & -.022 & .031 & .102 & $.644^{* *}$ & 1 & \\
\hline S-Rate & $.366^{* *}$ & $.221^{* *}$ & $.277^{* *}$ & $.164^{* *}$ & $.201^{* *}$ & $.315^{* *}$ & $.321^{* *}$ & -.013 & .032 & 1 \\
\hline
\end{tabular}

(3) Non-Indigenous (Urban) Students $(N=430)$

\begin{tabular}{|c|c|c|c|c|c|c|c|c|c|c|}
\hline & Sch-sc & Read-sc & Math-sc & Art-sc & Phy-sc & Enjoy & Partic & ReadAc & MathsAc & S-Rate \\
\hline School-sc & 1 & & & & & & & & & \\
\hline Reading-sc & $.678^{* *}$ & 1 & & & & & & & & \\
\hline Maths-sc & $.745^{* *}$ & $.459^{* *}$ & 1 & & & & & & & \\
\hline Art-sc & $.444^{* *}$ & $.401^{* *}$ & $.309^{* *}$ & 1 & & & & & & \\
\hline Physical-sc & $.454^{* *}$ & $.277^{* *}$ & $.431^{* *}$ & $.276^{* *}$ & 1 & & & & & \\
\hline Enjoyment & $.584^{* *}$ & $.532^{* *}$ & $.437^{* *}$ & $.357^{* *}$ & $.214^{* *}$ & 1 & & & & \\
\hline Participation & $.533^{* *}$ & $.499^{* *}$ & $.448^{* *}$ & $.331^{* *}$ & $.281^{* *}$ & $.576^{* *}$ & 1 & & & \\
\hline ReadAc & $.156^{* *}$ & $.266^{* *}$ & $.160^{* *}$ & .049 & -.017 & .094 & $.146^{* *}$ & 1 & & \\
\hline MathsAc & $.203^{* *}$ & $.184^{* *}$ & $.306^{* *}$ & .031 & $.121^{*}$ & .087 & $.131^{* *}$ & $.578^{* *}$ & 1 & \\
\hline S-Rate & $.437^{* *}$ & $.283^{* *}$ & $.404^{* *}$ & $.152^{* *}$ & $.262^{* *}$ & $.190^{* *}$ & $.303^{* *}$ & $.154^{* *}$ & $.185^{* *}$ & 1 \\
\hline
\end{tabular}

(4) Non-Indigenous (Rural) Students $(N=340)$

\begin{tabular}{|c|c|c|c|c|c|c|c|c|c|c|}
\hline & Sch-sc & Read-sc & Math-sc & Art-sc & Phy-sc & Enjoy & Partic & ReadAc & MathsAc & S-Rate \\
\hline School-sc & 1 & & & & & & & & & \\
\hline Reading-sc & $.597^{* *}$ & 1 & & & & & & & & \\
\hline Maths-sc & $.692^{* *}$ & $.400^{* *}$ & 1 & & & & & & & \\
\hline Art-sc & $.420^{* *}$ & $.360^{* *}$ & $.295^{* *}$ & 1 & & & & & & \\
\hline Physical-sc & $.350^{* *}$ & $.138^{*}$ & $.356^{* *}$ & $.227^{* *}$ & 1 & & & & & \\
\hline Enjoyment & $.543^{* *}$ & $.507^{* *}$ & $.375^{* *}$ & $.398^{* *}$ & $.143^{* *}$ & 1 & & & & \\
\hline Participation & $.503^{* *}$ & $.436^{* *}$ & $.464^{* *}$ & $.229^{* *}$ & $.210^{* *}$ & $.573^{* *}$ & 1 & & & \\
\hline ReadAc & $.273^{* *}$ & $.324^{* *}$ & $.196^{* *}$ & $.130^{*}$ & -.067 & $.189^{* *}$ & $.216^{* *}$ & 1 & & \\
\hline MathsAc & $.308^{* *}$ & $.203^{* *}$ & $.341^{* *}$ & $.114^{*}$ & $.145^{* *}$ & $.129^{*}$ & $.153^{*}$ & $.606^{* *}$ & 1 & \\
\hline S-Rate & $.411^{* *}$ & $.300^{* *}$ & $.373^{* *}$ & $.179^{* *}$ & $.162^{* *}$ & $.278^{* *}$ & $.334^{* *}$ & $.149^{* *}$ & $.164^{* *}$ & 1 \\
\hline
\end{tabular}

Note: $* * p<.01 . * p<.05$. 